\title{
LA GESTIÓN DE LA IMAGEN SUBJETIVA Y OBJETIVA DE LA EMPRESA EN LOS NUEVOS CANALES COMERCIALES
}

THE MANAGEMENT OF SUBJECTIVE AND OBJECTIVE IMAGE OF THE COMPANY IN THE NEW COMMERCIAL CHANNELS

Por: David López Jiménez*

*Doctor (con mención europea) en CC EE y EE y Doctor en Derecho

Grupo de investigación de excelencia GITICE (Universidad de Huelva -España-) dlopezjimenez@gmail.com; dlopez3@us.es

Artículo recibido: Septiembre 9 de 2011. Artículo aprobado: Noviembre 03 de 2011

\section{RESUMEN}

La reputación corporativa es un valor difícil de crear, pero muy fácil de perder. Tal aspecto se proyecta tanto en el mundo tradicional como en el escenario virtual. En la formación de la imagen empresarial influyen numerosos factores, si bien, en la actualidad, los instrumentos sociales presentes en Internet amplifican los efectos, positivos o negativos, respecto a la misma. Una vez cuantificada, podrá monitorizarse para realizar las medidas pertinentes.

Palabras clave: cliente; empresa; estrategia; on-line; reputación.

\section{ABSTRACT}

The corporate reputation is a value that is difficult to create, but that is very easy to lose. This aspect can be seen in both the traditional world and in the virtual environment. In the creation of the image of a corporation several factors take part. For this reason, it is appropriate to take into consideration, that nowadays social networks maximize the effects, positive or negative, used to support such a corporate image. Once it is quantified, it is controlled and the appropriate actions to monitor this image will be taken.

Keywords: customer; business; strategy; on-line; reputation

\section{Introducción}

La Web social o Web 2.0 representa uno de los aspectos más significativos de los últimos tiempos. De hecho, aunque ya se habla de Web 3.0 o Web 4.0, todavía no puede darse, ni mucho menos, por finalizado su impacto. Sus efectos son especialmente visibles sobre la realidad empresarial.

Durante los primeros años de la última década del siglo pasado ya existía cierta sociabilidad. Así, acontecía en los primeros foros electrónicos y newsgroups. En virtud de la Web 2.0 se han puesto en práctica numerosas plataformas específicamente diseñadas para la sociabilidad online. En otros términos,

Artículo de reflexión según clasificación Colciencias. 


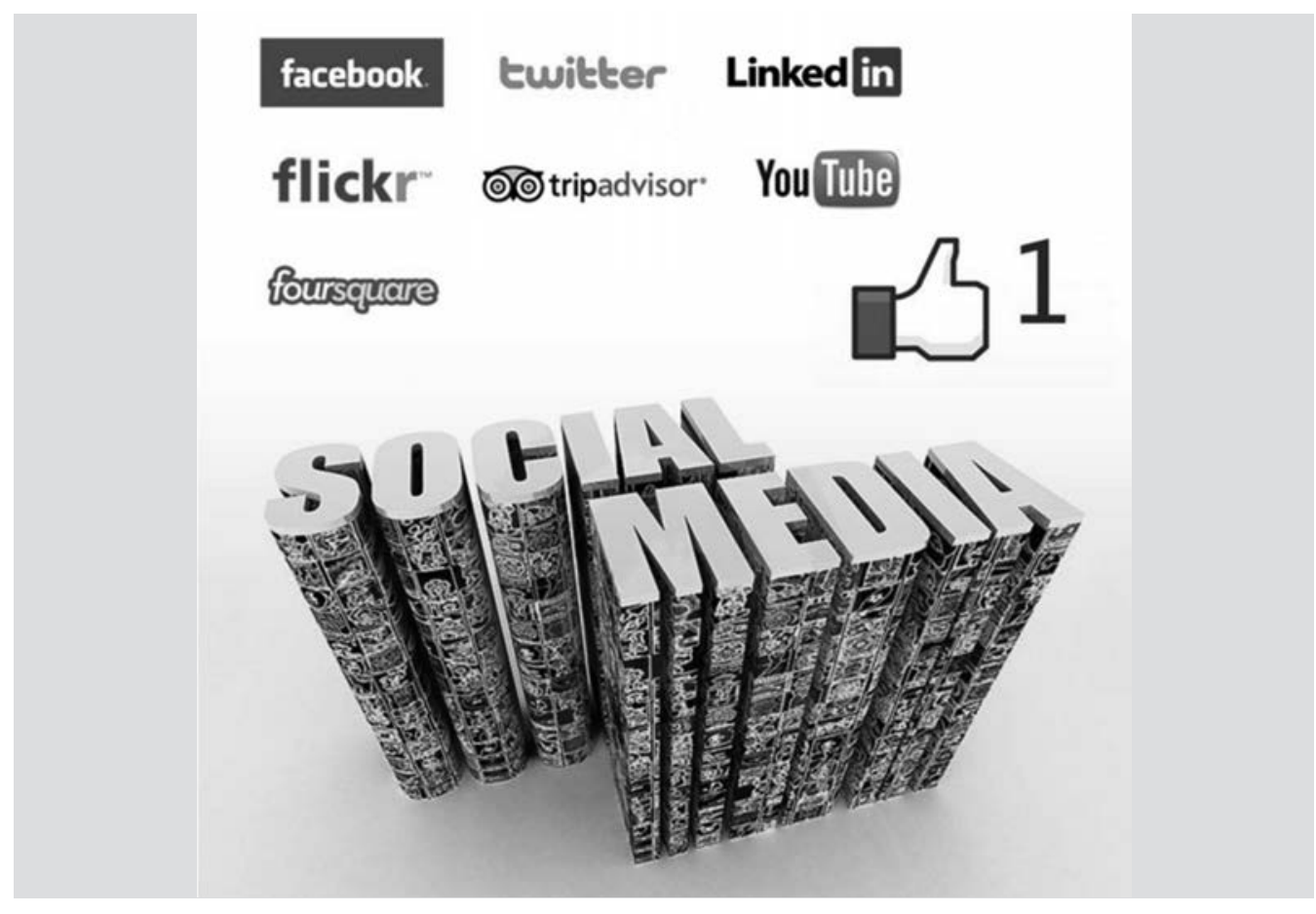

Redes Sociales

comunicaciones ha traído consigo el surgimiento de nuevas posibilidades para la sociedad. Entre las mismas, ocupa un lugar muy destacado Internet. En este último, se han ideado y consolidado plataformas de marcado carácter social como los blogs, wikis y redes sociales.

La llegada de la misma ha supuesto una revolución, pues el potencial usuario adquiere un nuevo papel dentro del soporte, ya que deja de ser un mero espectador de contenidos, para ser el que elige, el que participa e, incluso, el que crea esos contenidos. Gracias a tales plataformas, los usuarios se convierten en generadores, individuales y colectivos, de un enorme elenco de contenidos sobre múltiples contenidos. En cierta medida, podría afirmarse que la labor desarrollada por los usuarios se erige en una suerte de micromedios que, de manera colectiva, han entrado, en cierto sentido, en competencia sobre los medios de comunicación de corte tradicional.

En otras palabras, en la época actual, en la Red, la empresa no es el único emisor o sujeto activo del mensaje publicitario y el consumidor y/o usuario el sujeto pasivo. En efecto, a día de hoy, tales funciones, propias de cada uno de los colectivos en el pasado, sobre todo en el mundo físico, han evolucionado. La influencia pretérita de las marcas se construía en virtud de diferentes elementos, como, entre otros, la publicidad, las relaciones públicas y la comunicación en los medios. Con la puesta en práctica de la Web 2.0, 
las audiencias se dividen en micromedios integrados por un importante componente social y relacional. Estos últimos tienen la capacidad de crear y, a su vez, distribuir información complementaria y, en su caso, alternativa a los medios de comunicación de tipo decimonónico. De este modo, podemos afirmar que dan origen a un nuevo modelo de influencia e información. Este nuevo modelo, qué duda cabe, da lugar a un notable cambio de dirección de la influencia en las personas, en su papel como consumidores. Tal proceder repercute sobre la reputación virtual de la empresa que, dicho sea de paso, ha de distinguirse del concepto de responsabilidad social corporativa (RSC).

Aunque la reputación on-line representa un concepto difícil de medir, se han ideado herramientas específicas al efecto. De esta manera, si resulta procedente, podrá monitorearse para acometer su mejora. Una de las vías que puede desempeñar una extraordinaria labor es el fenómeno de la autorregulación. En efecto, pondremos de relieve cómo las diversas manifestaciones del fenómeno de la autodisciplina puede ser útil para mejorarla. Ahora bien, un incumplimiento de los compromisos asumidos voluntariamente por la empresa, en virtud de la autorregulación, puede representar una pérdida notable de la reputación inicialmente consolidada.

\section{La reputación virtual como novedosa manifestación corporativa}

\subsection{Delimitación conceptual}

La reputación empresarial ha sido una cuestión abordada por parte de diferentes disciplinas. Dentro de estas últimas, por ser una materia más propia de las mismas, ha merecido un amplio examen desde las ciencias empresariales. Asimismo, uno de los principales escollos que han de abordarse en relación a la cuestión que comentamos es de carácter terminológico. En efecto, dado que la reputación corporativa, es empleada por un notable elenco de disciplinas -desde la sociología hasta la teoría de los juegos- y que cada una presenta su propio concepto, es extraordinariamente difícil ofrecer una definición estandarizada (Deephouse, 2000).

En este sentido, sin perjuicio de que ostenta cierta multidimensionalidad (Fombrun y Shanley, 1990; Dollinger, Golden y Saxton, 1997; Ferguson, Deephouse y Ferguson, 2000) e intangibilidad (Barney, 1991), se define como el conocimiento de las verdaderas características de una empresa y las emociones que hacia ellas muestran los grupos de interés de la misma-entre 
los que se encuentran los consumidores y/o usuarios-. Por consiguiente, es fruto de la percepción representativa de la compañía basada tanto en su actuación en el pasado como en su proyección futura (Fombrun, 1996). También se ha puesto de relieve que constituye un concepto emocional, difícil de racionalizar y de expresar con palabras (Groenland, 2002). Obviamente, la misma podrá tener carácter positivo o negativo.

El concepto que examinamos, qué duda cabe, tiene cierta influencia sobre la creación de valor (De Quevedo, 2003; De Quevedo, De La Fuente y Delgado, 2005). De hecho, una buena reputación supone beneficios superiores (Landon y Smith, 1997), lo que indudablemente facilita la solidez de la empresa en cuestión en el corto y medio plazo (Teece, Pisana y Shuen, 1997). Además, puede, entre otros aspectos, representar: un aumento del valor bursátil y atracción de nuevas inversiones; mayor seguridad en la adopción de decisiones de carácter estratégico; adelantamiento a las nuevas tendencias en el ámbito de la gestión de la reputación: capitalización de oportunidades y, en su caso, identificación de posibles riesgos emergentes; perfeccionamiento de la confianza y de la credibilidad, por parte de la empresa, ante los diferentes stakeholders; sustancial mejora de la oferta comercial de la compañía; atracción de nuevos clientes, dado que se atraerá tráfico de calidad al sitio Web; mejora de la imagen del sitio Web corporativo de la empresa, ya que los comentarios positivos redundarán en su prestigio; puesta en práctica de una política de comunicación más eficaz; retención del talento de las empresas; un escudo relevante frente a posibles crisis; $y$, en definitiva, un fortalecimiento del liderazgo de la empresa.

Tales apreciaciones pueden extrapolarse al espacio virtual. En ese caso, podríamos manifestar que la reputación on-line es la valoración alcanzada por una determinada empresa $-\mathrm{y}$, por ende, de sus productos $\mathrm{y} / \mathrm{o}$ servicios- $\mathrm{a}$ través del uso o mal uso que ofrece Internet.

\subsection{Diferenciación de figuras afines: la Responsabilidad Social Corporativa (RSC)}

Las empresas, en la actualidad, coexisten en un contexto altamente competitivo que les obliga a realizar una diferenciación, en todos los sentidos, para poder subsistir en los mercados internacionales. En efecto, necesitan encontrar nuevas fuentes de ventaja profesional que les permitan ser competitivas en el tiempo. Es aquí donde radica la importancia de la RSC en el mundo 
de los negocios que hoy en día conocemos. La RSC constituye un elemento condicionante, y también podría decirse que integrante, de la estrategia empresarial, tanto a nivel corporativo -condicionará el tipo de actividad y el lugar donde se vaya a desarrollar- como de negocio -influirá en la forma de competir-.

El término RSC no tiene, a tenor de las consideraciones doctrinales actualmente existentes, un significado unánime, si bien entendemos que representa una expresión cercana a la comunicación de los valores. Aun así, debe valorarse que la RSC, en la actualidad, continúa siendo un término todavía difuso que se traduce en actuaciones y objetivos diferentes en función de la empresa, entidad u organización que la integra. En consecuencia, no parece fácil dar una definición relativamente consensuada de la RSC (Guardia y Vallés, 2007).

Sin perder de vista las consideraciones expuestas, la RSC puede definirse como el conjunto de obligaciones y compromisos -de carácter legal y éticonacionales e internacionales, con los grupos de interés, que se derivan de los impactos que la actividad y operaciones de las organizaciones producen en el ámbito social, laboral, medioambiental y de los derechos humanos. En consecuencia, puede afirmarse que la RSC afecta a la propia gestión de las organizaciones, tanto en sus actividades productivas y comerciales, como en sus relaciones con los grupos de interés (De la Cuesta González y Valor Martínez, 2003).

En cualquier caso, entendemos que procede efectuar una doble consideración. Por un lado, la RSC no es un fin ni un medio, sino que es un principio básico que debe regir, en toda su amplitud, el conjunto de las actuaciones empresariales que debe estar presente en el razonamiento previo a cualquier toma de decisión (Bajo Sanjuán, 2007). Por otro, que la RSC está muy relacionada con la predisposición de llevar el comportamiento empresarial a un nivel superior en el que sea congruente con las normas, valores y expectativas sociales de todos los grupos existentes y próximos a la organización, pero sin olvidar la prioridad económica de su naturaleza y las imposiciones normativas nacionales.

La RSC y la reputación corporativa están muy relacionadas entre sí. De hecho, en numerosas ocasiones, se pueden llegar a confundir. En este sentido, la propia prensa económica, con relativa habitualidad, hace uso de ambos términos, relacionándolos. Asimismo, la estructura organizativa de las empresas, en 
numerosos supuestos, tiene fusionados, en un mismo departamento, la gestión de la RSC y de la reputación corporativa.

En cuanto a las similitudes y diferencias que existen entre las mismas, cabe disponer que la principal analogía es que ambas (la RSC y la reputación corporativa) se basan en la relación de la empresa con los diversos grupos participantes. No obstante, la diferencia más relevante estriba en que, mientras que la RSC persigue recoger objetivamente las actuaciones y actitudes de la empresa en el compromiso con sus participantes, la reputación corporativa está marcada por su contenido informativo y perceptivo. En otras palabras, la RSC representa un elenco de acciones o políticas caracterizadas por la gestión de la empresa, mientras que la reputación corporativa desborda del control de la organización originándose en los propios agentes económicos.

A pesar de la diferencia esencial a la que se acaba de hacer alusión, presentan una estrecha relación, ya que las percepciones nacen en la mente de los agentes económicos a partir de la información que reciben del mundo que les rodea. De esta manera, la reputación corporativa es la condensación de las percepciones que generan los propios agentes económicos al observar el comportamiento de la empresa en el escenario institucional que le rodea. Aunque la reputación corporativa nace en la mente de los participantes de la empresa, su gestión puede modular, de manera indirecta, estas percepciones en virtud de los comportamientos que mantiene con los participantes. En consecuencia, la RSC reside en la propia organización, si bien la reputación corporativa se encuentra en la mente de los stakeholders. En otras palabras, podríamos afirmar que la RSC está más relacionada con la acción, mientras que la reputación corporativa con la comunicación.

Como hemos visto, la RSC y la reputación corporativa, aunque son conceptos muy parecidos, son diferentes. En efecto, mientras que la RSC trata de describir objetivamente el comportamiento de la compañía en cada una de las relaciones, la reputación corporativa recoge las percepciones de cada uno de los participantes en relación a la empresa. Como es de suponer, la empresa no puede, en modo alguno, controlar las percepciones que tienen lugar en los cerebros de los diferentes agentes económicos, pero lo que, sin embargo, sí está bajo su control son los comportamientos que mantiene en las relaciones con los diversos participantes y que indirectamente están relacionadas con las percepciones. En consecuencia, la gestión de la RSC es parte de la gestión activa de la reputación corporativa. A contrario sensu, la gestión de la reputación 
corporativa resulta de mayor amplitud que la RSC. Solo nos encontramos con una sola RSC, mientras que respecto a la reputación corporativa existe una enorme variedad. En efecto, no debe olvidarse que puede ser muy diversa entre los diversos stakeholders.

La RSC forma parte de la reputación corporativa, dado que, asimismo, no debería darse la segunda -una buena reputación corporativa- sin la primera. $\mathrm{O}$, en otras palabras, de producirse, no debería poder mantenerse en el largo plazo esta ventaja competitiva sin una buena praxis que la respalde.

\subsection{Incidencia de Internet sobre el particular}

Las nuevas plataformas participativas y los servicios de creación conjunta interactiva en los que los usuarios han pasado a ser actores, productores o "productores-consumidores" activos brindan una oportunidad sin precedentes para dar rienda suelta a la creatividad de los partícipes de la Red. Es esencial crear un entorno y una cultura de apertura y confianza que fomente este desarrollo.

La tendencia actual de los servicios que la Red pone al alcance del usuario foros, blogs, y redes sociales- se construye desde un nexo común que tiene en su base la actividad colaborativa. En otros términos, todas aquellas utilidades y servicios de Internet que se sustentan en una determinada base de datos que, a su vez, puede ser modificada, tanto en su forma como en su contenido, por los propios usuarios del servicio.

Las redes sociales son servicios prestados a través de Internet que permiten a los usuarios generar un perfil público -o, lo que es lo mismo, para todos los usuarios de la red sin restricciones- o semipúblico -únicamente para los contactos personales previamente admitidos por el interesado- en el que se podrán, con cierta amplitud, reflejar datos personales. A su vez, se dispondrá de herramientas informáticas que permiten interactuar con el resto de usuarios de esa red social. Cuando se habla de estas últimas, se alude a plataformas electrónicas desde las que los usuarios previamente registrados pueden interactuar mediante mensajes, compartir información, imágenes y/o videos que podrán ser vistos por sus contactos habilitados.

El blog existe desde los orígenes de la misma Red. Aunque, inicialmente, no era demasiado popular, su uso, en la actualidad, resulta creciente (BBC Online, 
2006), siendo extraordinariamente conocido. Es un diario virtual que contiene reflexiones, comentarios y enlaces con otros sitios digitales (Cornett, 2009). Presenta un orden cronológico inverso (Blood, 2002) -se consulta comenzando por el último comentario insertado-, situado en un sitio Web, en el cual su autor vierte opiniones, reflexiones, enlaces a otras páginas Web u otros blogs, con la posibilidad de que distintos internautas introduzcan sus comentarios que podrán ser controlados, e incluso, si procede, censurados, por el titular del blog, que se denomina blogger.

Existen diferentes modalidades de blogs, a saber: personales, temáticos y corporativos. En el caso de los blogs personales, su autor suele expresar su punto de vista sobre una enorme variedad de cuestiones. Así, por ejemplo, puede tratarse de asuntos de actualidad, temas de ocio o, incluso, de carácter profesional. Si el blog está especializado en una determinada materia puede afirmarse que el mismo presenta carácter temático. Dichas herramientas pueden dar lugar a comunidades virtuales que, dado el elevado grado de especialización, influyan sobre los hábitos de numerosos consumidores y/o usuarios. Un blog corporativo, que frecuentemente está en manos de un trabajador de la empresa a la que aluda, representa una herramienta muy adecuada para comunicar los productos, valores y cultura de la misma. El blog, en esa variante - de la que, a su vez, existen diversas modalidades (blog de marca; blog de productos o servicios; blog de empleados; blog de eventos; y blog del sector)-, es un instrumento de marketing idóneo tanto para fortalecer relaciones con los clientes como con los proveedores y tiene, o podría tener, un impacto en la mejora de los resultados de actividades de comercio electrónico de la compañía. En definitiva, son una extraordinaria herramienta de comunicación bidireccional con los clientes y los medios, dado que fomentan la participación. No en vano los clientes pueden tener la percepción de que se les escucha, debido, en gran medida, a las respuestas y comentarios generados.

En cualquier caso, el mal uso o abuso de los blogs de empresa está creando una percepción negativa en los usuarios. Esa es una de las conclusiones que surge de una reciente encuesta efectuada por North American Technographics Media and Marketing Online, citada por Forrester Research en un estudio sobre la credibilidad de los blogs corporativos. Este determina, entre otros extremos, que los blogs tocan fondo en la escala de la credibilidad, alcanzando tan solo el 16\% de la confianza de los consumidores on-line. La herramienta electrónica que transmite mayor confianza, según el estudio que comentamos, es el correo electrónico de personas conocidas o del entorno (77\%) y las revisiones 
de productos y servicios (60\%). Por debajo de ese umbral de credibilidad se encuentran los portales con motores de búsqueda, las páginas amarillas en formato físico, los periódicos impresos, las redes sociales de gente conocida, las revistas impresas, la radio, los grandes sitios de contenidos on-line de periódicos o revistas de alta rotación, la televisión, Wikis, el correo electrónico corporativo, el marketing directo on-line, los mensajes en listas de discusión, los blogs personales, las redes sociales corporativas y, por último, los blogs corporativos con un 16\% de credibilidad.

Debe considerarse que los blogs corporativos ocupan una posición muy destacada en la estrategia de marketing electrónico. De hecho, el estudio de referencia al que hemos aludido, dispone que los consumidores que han señalado que creían en los blogs, también han manifestado que los mismos son la fuente de información en la que más confían -con respecto a cualquier otra fuente-. Hay, por tanto, un público fiel a los blogs que constituye un nicho interesante para la comunicación corporativa.

Dichas herramientas de comunicación son, como regla general, de carácter no invasivo. En efecto, el internauta que desee recibir los últimos eventos acontecidos en las mismas -ya sea en forma de comentarios, de modificaciones o, en suma, de actualizaciones- deberá haber tenido que suscribirse con carácter previo. Tal aspecto supondrá que las comunicaciones que el usuario reciba en su bandeja de correo electrónico habrán sido voluntariamente solicitadas, por lo que no podrán ser reputadas como spam.

\subsection{Instrumentos de cuantificación y monitoreo}

La reputación empresarial resulta visible tanto en el mundo físico u off-line como en el espacio virtual u on-line. Por lo que a la última de ellas respecta, que naturalmente se proyecta en el mundo tradicional, cabe señalar que es una de las áreas de mayor preocupación para los directivos de empresa. De hecho, como seguidamente veremos, resulta pertinente diseñar tanto procesos internos como externos en la gestión de la reputación en la Web social. Al hilo de cuanto manifestamos, deben hacerse dos apreciaciones. Por un lado, que mientras más visible sea una determinada empresa menos dominio tendrá sobre su imagen en la Web. Y, por otro, que las opiniones o juicios de valor que tienen lugar en los diversos instrumentos colaborativos de la Red, como los blogs y las redes sociales, aportan gran parte de la reputación corporativa online, siendo la parte restante responsabilidad del propio sitio Web corporativo. 
Nos encontramos ante un valor intangible -la reputación on-line- que es posible identificar y analizar a través de las valoraciones que los usuarios efectúan en diversas plataformas de la Red. De hecho, tales sitios Web, en numerosas ocasiones, han sido concebidos, para precisamente expresar opiniones en relación a determinadas empresas, marcas, productos y/o servicios de las organizaciones empresariales.

Grosso modo, podría afirmarse que el procedimiento para el monitoreo consiste tanto en la delimitación como en la estrategia de búsqueda y rastreo Web. $\mathrm{O}$, lo que es lo mismo, en la creación de un patrón de reconocimiento basado en las características del texto independiente del tipo de plataforma online dónde se encuentre en virtud del reconocimiento de keywords. Dado que las búsquedas son realizadas de manera sintáctica es necesaria la definición y establecimiento de filtros, reglas de inclusión y exclusión, de resultados que extraigan información propia y significativa de la temática objetivo. Por último, es precisa una revisión y ajuste, refinado, de las keywords y de las reglas definidas durante en el inicio de la monitorización que permita la generación de forma automática y continua, sin ningún tipo de intervención manual y sin elevados conocimientos lingüísticos, para obtener un universo de datos relevante.

Aunque su cuantificación resulta extraordinariamente compleja, se han ideado herramientas dirigidas a tal fin (Dwyer, 2007). Así, por ejemplo, para acometer la medición de la misma en la Red, empresas como la estadounidense Nielsen -especializada en la medición y análisis de audiencias en Internet- ha lanzado en España Buzzmetrics. Representa una herramienta capaz de analizar los comentarios realizados en más de 70 millones de blogs y unas 100.000 comunidades de consumidores y/o usuarios on-line. Se estima que controla, en tiempo real, más de tres billones de comentarios que circulan en la Red. Dicho instrumento facilita el análisis cualitativo de las opiniones y contenidos generados en los blogs, newsgroups, foros y redes sociales.

Swotti representa un buscador especializado en rastrear opiniones públicas efectuadas en la Web 2.0 en relación a todo tipo de marcas, productos y/o servicios. Se fundamenta en una tecnología basada en la Web semántica que permite a cualquier empresa conocer, de manera relativamente rápida, la valoración mayoritaria en la Red en relación a un determinado bien y/o servicio.

PalObra No. 12. Agosto de 2010 - Julio de 2011 
Por otro lado, Keotag constituye una herramienta que se apoya sobre la marcación social. En este sentido, se escribiría la palabra o término en el que el usuario esté interesado, ofreciéndose resultados de los impactos en dieciséis plataformas diferentes de la Web social como, entre otros, Twitter, Del.icio.us, Flickr, MySpace y YouTube.

Otros instrumentos aptos para su medición son, entre otros, los siguientes: los denominados lectores de sindicación de contenidos (RSS); el buscador Technorati que, además de poder indexar los contenidos de la blogosfera, ostenta ciertas funcionalidades que le permite rastrear y analizar un número extraordinariamente alto de opiniones; creación de alertas con la finalidad de detectar posibles crisis como Google Alerts, Technorat Wacht List o en virtud de herramientas RSS.

Una vez que la misma -la reputación virtual- se ha medido, podrá gestionarse para, en su caso, mejorarla. En otros términos, los consumidores y/o usuarios comparten sus opiniones sobre productos y/o servicios, personas y organizaciones en diferentes espacios. Se trata de foros, blogs, redes sociales y sitios Web dedicados exclusivamente a valoraciones. En otras palabras, en la época actual, en la Red, la empresa no es el único emisor o sujeto activo del mensaje publicitario y el consumidor y/o usuario el sujeto pasivo. En efecto, a día de hoy, tales funciones, propias de cada uno de los colectivos en el pasado, sobre todo en el mundo físico, han evolucionado. De esta manera, un determinado consumidor y/o usuario puede pronunciarse en la Red sobre un producto y/o servicio y en relación a la empresa que lo comercializa. Tal valoración podrá, asimismo, ser susceptible de influir, en cierto sentido, en la conducta del público potencialmente destinatario.

\section{La integración en sistemas de autodisciplina empresariales: efectos de carácter positivo y negativo}

Una vez que hemos visto, de manera somera, el concepto y caracteres esenciales de varias de las manifestaciones de la red colaborativa, cabe seguidamente aludir a la relevancia que en tales espacios ostenta la autorregulación. A este respecto, se ha puesto de relieve que la falta de normas que, de alguna manera, disciplinen esta materia podría recordar, a juicio de la doctrina, al oeste salvaje. Esta última, la autorregulación, con relativa habitualidad, adopta el formato de códigos de conducta. Estos últimos normalmente incluyen, en un solo documento, la normativa imperante más un plus adicional de mejora para los destinatarios a los que el mismo alude. 
Ahora bien, la virtualidad que los códigos de conducta despliegan en el caso concreto de los blogs, sin perjuicio de contener, en limitados supuestos, alguna norma residual de su articulado dedicada a la tutela de privacidad, se centra en la necesidad de observar ciertas normas de comportamiento mínimas en tales espacios. Así, por ejemplo, cabe referirse, por su relativa popularidad, al código de conducta para blogs redactado por Tim O'Reilly, de la editorial O 'Reilly, así como por Jim Wales de Wikipedia. La aprobación del mismo tuvo lugar como consecuencia de desafortunados incidentes acaecidos en los Estados Unidos entre diversos bloggers. Entre las normas incluidas en tal documento, cabe citar: asume la responsabilidad no sólo por tus propias palabras, sino también sobre los comentarios que permites en tu blog; etiqueta tu nivel de tolerancia para comentarios abusivos; considera eliminar los comentarios anónimos; ignora a los trolls -es decir, personas que sólo buscan provocar intencionadamente a los usuarios o lectores-; continúa la conversación fuera de Internet, habla directamente, o encuentra a un intermediario que pueda hacerlo; si conoces a alguien que se está comportando mal, hazlo saber; y no digas nada on-line que no podrías decir en persona. Existen otros con un contenido parcialmente similar como el redactado por CyberJournalist.net que se fundamentó en el código ético elaborado, al efecto, por la sociedad de periodistas profesionales. Por consiguiente, en estos dos últimos casos, no nos encontraremos ante lo que podrá denominarse un verdadero sistema de autorregulación por dos motivos.

En primer lugar, los códigos de conducta, que serán de carácter unilateral -pues habrán sido redactados por los responsables del blog-, no innovan, en modo alguno, el ordenamiento legal imperante, reconociendo nuevos derechos, a favor de su potencial destinatario, ya que básicamente incluyen normas de comportamiento en las comunidades para las que han sido aprobadas. Dicho de otra manera, constituyen un elenco de buenas prácticas que persiguen fomentar conversaciones constructivas que respeten las formas personales de expresarse, limitando, de esta manera, la mala educación y a las actitudes incivilizadas. Para, precisamente, evitar la edición de comentarios potencialmente inapropiados, agresivos, o denigratorios, los administradores de los blogs podrán condicionar su publicación definitiva a su visto bueno. No obstante, lo que no parece correcto, en el caso de los blogs corporativos, es que, bajo tal excusa, se puedan censurar los comentarios potencialmente desfavorables para las empresas a las que se refieren o los productos y/o servicios de las mismas. Tal supuesto se ha planteado en la práctica. En este 
sentido, conviene manifestar el caso en el que un usuario se quejó, en el blog del Director de Marketing de la unidad de software de gestión de Hewlett Packard, por la mala experiencia que tuvo en relación con un determinado producto. Dado que la opinión era desfavorable a los intereses de la compañía, el directivo lo eliminó. Sin embargo, el afectado lo hizo público, adquiriendo el suceso una extraordinaria difusión. Ante tal extremo, el directivo reconoció los hechos, pidiendo disculpas, procediendo a incluir, de nuevo, la valoración del internauta. Al hilo de cuanto planteamos, cabe determinar que ciertos blogs corporativos de Hewlett Packard incluyen en su articulado normas que expresamente establecen el respeto de las opiniones vertidas. De este modo, únicamente se eliminarían de infringir las normas de uso del código de conducta.

En segundo lugar, de ser transgredidos, la sanción que, como regla general, comportarán será la supresión del comentario inapropiado y, en su caso, la cancelación de la cuenta de usuario, cuyo titular haya vulnerado las normas de uso. En otras palabras, no existe organismo de control encargado de su verificación que también representa un presupuesto constituyente de los sistemas de autorregulación.

La adhesión a herramientas derivadas de la autodisciplina (cual, por ejemplo, son ciertas normas ISO, normas UNE, códigos de conducta, códigos tipo, marcas de garantía, terceros de confianza, etc.) podrá suponer una mejora en el nivel de reputación on-line de la empresa comprometida con tales instrumentos de buenas prácticas. Repárese en que, a nivel teórico, comportan un incremento de los derechos mínimos reconocidos por el legislador a favor del potencial consumidor y/o usuario. Este aspecto será, como regla general, valorado positivamente, por parte de los potenciales consumidores y/o usuarios, pues será percibido como una ventaja competitiva frente a sus competidores directos e indirectos.

Ahora bien, en el supuesto de que las empresas adheridas incumplan tales compromisos voluntariamente asumidos, incurrirán en una pérdida considerable del nivel de reputación on-line que, en un determinado espacio temporal, pudo alcanzarse. Nótese que la declaración de haber quebrantado las normas incluidas en el articulado de los mismos podrá ponerse de manifiesto por parte de las resoluciones de los organismos de control establecidos en el ámbito de los sistemas de autodisciplina. En las resoluciones de carácter condenatorio de la empresa adherida podrán 
imponerse diversos tipos de sanciones, a saber: solicitud de cese de la actividad eventualmente contraria al código de conducta suscrito; multa de tipo económico; y, en los supuestos más graves, expulsión publicitada de la empresa incumplidora.

El articulado de las herramientas en las que se manifiesta la autorregulación, pueden, y, de hecho, es frecuente que en la práctica así acontezca, incluir, además de la legislación imperante, un plus adicional. Este último, en ocasiones, será de carácter ético, lo que supone que los empresarios adheridos podrían incurrir en infracciones que, por el contrario, podrían no concurrir en el caso de estar sometidos únicamente a las leyes vigentes.

Tal supuesto deberá ser claramente diferenciado de aquel otro en el que el organismo de control del sistema de autorregulación se pronuncie sobre la reclamación formulada frente a una empresa no adherida $-\mathrm{O}$, lo que es lo mismo, un tercero ajeno-. La resolución que, en su caso, dicte el organismo de control podrá poner de relieve la violación de alguna de las normas éticas del código de conducta, que no está obligado a respetar. Es más, el contenido de la resolución, podría llegar a ser, en algunos casos, eventualmente denigratoria. Por tanto, podrá verse perjudicada la reputación virtual que, hasta ese momento, tenga la empresa a la que la misma aluda. A ello inexorablemente contribuiría el uso de la Red, pues, al facilitar extraordinariamente su difusión -al recurrir a blogs y/o redes sociales-, amplificaría los efectos potencialmente negativos.

\section{Conclusiones}

En la actualidad, la identidad y reputación corporativa discurre por dos caminos de carácter convergente: el mundo físico o tradicional y el espacio virtual u on-line. Internet repercute sobre ambos.

Cuando estamos interesados en una empresa o un producto y/o servicio, cada vez en mayor medida, se recurre a la red de redes. En efecto, con relativa habitualidad, en los buscadores se introducen términos susceptibles de aludir a los intereses del usuario. Lo que, sobre el particular, se encuentre podrá condicionar la actitud del interesado.

Podría afirmarse que el concepto decimonónico del vocablo reputación continúa, en esencia, siendo el mismo. De hecho, como es sabido, versa sobre 
la valoración que los terceros tienen respecto a una determinada empresa. Ahora bien, Internet permite que un número importante de personas puedan estar opinando simultáneamente sobre una empresa concreta y/o los bienes o servicios asociados a la misma.

La Web 2.0 -blogs, redes sociales y foros- ha supuesto un cambio de rol de los agentes. En la actualidad, los usuarios han dejado de tener un papel pasivo -Web 1.0-, protagonizando una actitud activa. Las opiniones y comentarios efectuados en los mismos, pueden repercutir, positiva o negativamente, sobre la reputación virtual. En efecto, la imagen de una determinada empresa puede verse afectada por las valoraciones que se efectúen en virtud de las herramientas sociales. Tales opiniones, qué duda cabe, serán susceptibles de afectar, con extraordinaria celeridad y a tiempo real, sobre las ganancias de la compañía. Aunque la reputación on-line se encuentra estrechamente relacionada con la RSC son diferentes.

Se han ideado diferentes herramientas para cuantificar y posteriormente monitorizar la reputación virtual. Entre las mismas, cabe, entre otras, enunciar Buzzmetrics; Swotti; Keotag; lectores de sindicación de contenidos (RSS); el buscador Technorati; alertas con la finalidad de detectar posibles crisis como Google Alerts; Technorat Wacht List; o en virtud de herramientas RSS. Solo una vez que la misma se ha cuantificado, podrá gestionarse para, si es preciso, mejorarla.

La gestión de la reputación virtual representa un elemento fundamental para que las empresas puedan infundir confianza. Su adecuada gestión representa una fuente de ventajas competitivas, si bien su descuido puede dar origen a ciertas crisis.

Resulta, por consiguiente, necesaria una respuesta de las propias empresas con la finalidad de evitar daños que puedan minar su activo intangible más significativo que no es sino la reputación corporativa.

Finalmente, la integración en sistemas de autodisciplina puede repercutir en la reputación virtual. La simple adhesión constituye una decisión de carácter positivo, si bien una actuación irresponsable al efecto, puede suponer una pérdida importante de los niveles de reputación inicialmente alcanzados. 


\section{BIBLIOGRAFIA}

BAJO SANJUÁN, A. (2007) “¿De qué estamos hablando al referirnos a la RSC?”. En BAJO SANJUÁN, A. y VILLAGRA GARCÍA, N. (Eds.), Evolución conceptual y práctica de una gestión responsable, Servicio de Publicaciones de la Universidad Pontificia de Comillas, Madrid.

BARNEY, J.B. (1991) "Firm resources and sustained competitive advantage", Journal of Management, Vol. 17, núm. 1.

BBC Online (2006) "Blogosphere sees healthy growth", BBC Online, 11 de agosto de 2006.

BLOOD, R. (2002) The weblog handbook: practical advice on creating and maintaining your Blog, Perseus Publishing, Cambridge, MA.

CORNETT, J.M. (2009) "The Ethics of Blawging: A Genre Analysis", Loyola University Chicago, Vol. 41.

DE LA CUESTA GONZÁLEZ, M. y VALOR MARTÍNEZ, C. (2003) “Responsabilidad social de la empresa. Concepto, medición y desarrollo en España", Boletín Económico del ICEI, núm. 2755.

DE QUEVEDO, E. (2003) Reputación y creación de valor. Una relación circular, $1^{\text {a }}$ ed., Paraninfo, Madrid.

DE QUEVEDO, E. DE LA FUENTE, J.M. y DELGADO, J.B. (2005) “Reputación Corporativa y Creación de Valor. Marco Teórico de Una Relación Circular", Investigaciones Europeas de Dirección y Economía de la Empresa, Vol. 11, núm. 2.

DEEPHOUSE, D.L. (2000) "Media reputation as strategic resource: an integration of mass comunication and resource-based theories", Journal of Management, Vol. 26.

DOLIINGER, M.J. GOLDEN, P. y SAXTON, T. (1997) "The effect of reputation on the decision to joint venture", Strategic Management Journal, Vol. 18, núm. 2.

DWYER, P. (2007) "Measuring the value of electronic word of mouth and its impact in consumer communities", Journal of Interactive Marketing, Vol. 21, núm. 2.

FERGUSON, T.D. DEEPHOUSE, D.L. y FERGUSON, W.L. (2000) "Do strategic groups differ in reputation?", Strategic Management Journal, Vol. 21, núm. 12.

FOMBRUN, C.J. (1996) Reputation: Realising value from the corporate image, Harvard Business School Press, Boston.

FOMBRUN, C.J. y SHANLEY, M. (1990) "What's in a name?: Reputation building and corporate strategy", Academy of Management Journal, Vol. 33, núm. 2.

GROENLAND, E.A. (2002) "Qualitative research to validate RQ-Dimensions", Corporate Reputation Review, Vol. 4, núm. 4.

GUARDIA, R. y VALLES, I. (2007) "Responsabilidad social de la empresa: identidad y valor de la marca". En HERNÁNDEZ ROBLEDO, M.A. LOSADA VÁZQUEZ, A. y MACÍAS CASTILLO, A. (Coords.), Estrategia y conducta social de la organización, Publicaciones de la Universidad Pontificia de Salamanca, Salamanca.

LANDON, S. y SMITH, C.E. (1997) "The use of quality and reputation indicators by consumers: The case of Bordeaux wine", Journal of Consumer Policy, Vol. 20, núm. 3.

TEECE, D.J. PISANA, G. y SHUEN, A. (1997) "Dynamic capabilities and strategic management", Strategic Management Journal, Vol. 18, núm. 7.

PalObra №. 12. Agosto de 2010 - Julio de 2011 